If a body is convex and has area $A$, it was proved by Cauchy that $A$ is equal to four times the mean of the area of the projection of the body on a plane for all orientations of the latter. This result has a limited application in the estimation by photographic or photometric means of the average surface area of a number of small particles suspended in a liquid. With larger particles such as stones, however, it sug. gests that the area of projection should be measured in a number of different directions by some such optical method. The average of these multiplied by four will give the surface area. In order to give equal weight to each observation it is desirable to choose the directions of projections to be those of the normals to a dodecahedron or an icosahedron.

The question then arises as to how good an approximation this is to the true mean. If $A$ is the true area and $A_{1}$ the area estimated by this method

$$
0.918 \leqslant \frac{A_{1}}{A} \leqslant 1.079
$$

for a dodecahedron, and

$$
0.955 \leqslant \frac{A_{1}}{A} \leqslant 1.047
$$

for an icosahedron. These limits are the approximate numerical values of certain trigonometrical expressions which can be evaluated exactly. They are, moreover, the best possible limits.

Proofs of the above results and some analogous theorems will appear in the Annals of Mathematics.

$$
\begin{aligned}
& \text { St. John's College, } \\
& \text { Cambridge. } \\
& \text { Sept. 1. }
\end{aligned}
$$$$
\text { P. A. P. Moran. }
$$

\section{A Solar Halo Phenomenon}

A DISPLAY of mock suns was seen here on the morning of August 9. Descriptions of similar displays seen at Cambridge and Godalming have been published ${ }^{1}$ and these notes are supplementary to them.

The Farnborough display occurred in cirrus caused by aircraft trails at a height of 20,000 ft. At 12.15 a.m. (D.S.T.) it consisted of a complete parhelic circle, about one third of a complete tangent arc, left-hand and right-hand coloured parhelia near the $22^{\circ}$ halo, two white parhelia situated on the parhelic circle and an anthelion. The colours were exceptionally brilliant.

The shape of the tangent arc was similar to that expected theoretically ${ }^{2}$ for the sun at an altitude of $48^{\circ} 07^{\prime}$ (its altitude at 12.15 a.m.). The colour bands in the left-hand parhelion were not perpendicular to the parhelic circle, but were inclined to the vertical at an angle of about $30^{\circ}$. They also extended slightly below the parhelic circle in a manner similar to the arcs of Löwitz. Some photographs taken by $\mathrm{Mr}$. Brock show this inclination. They were made on Ilford Standard Panchromatic film with a tri-red filter : the range of wave-lengths recorded was from $5800 \mathrm{~A}$. to $6700 \mathrm{~A}$. A measurement on the best of the photographs gives, as the distance from the inside of the $22^{\circ}$ halo to the inside boundary of the left-hand parhelion, $8^{\circ} 44^{\prime} \pm 30^{\prime}$ (extreme error). This distance has been calculated to be $9^{\circ} 31^{\prime}$, assuming a refractive index of 1.307 for ice (corresponding to a temperature of $-10^{\circ} \mathrm{C}$. and a wave. length of $6700 \mathrm{~A}$.) and a solar altitude of $48^{\circ} 07^{\prime}$. As it has been assumed that the sun is a point source, the agreement seems satisfactory.
The bands seen by Mr. Archenhold were also seen here; but according to our notes they were coloured, even when they passed through the sun. This indicates a diffraction origin for the colours. Unfortunately, it was not noticed whether the red or violet was nearer the sun; such an observation would have distinguished a refraction origin from a diffraction origin. We think that Mr. Archenhold's explanation is too simple, since it is geometrically impossible for a collection of reflecting and refracting elements between earth and sun to produce a straight band of light not passing through the sun, except for unlikely distributions of orientation.

It is evident that knowledge of atmospheric optics is still in an elementary state, and that many more careful (preferably photographic) observations are required. That England is not an unsuitable country for these observations is shown by the fact that, during the five weeks following the display, we have seen fifteen $22^{\circ}$ solar halos, three brightly coloured parhelia, one isolated upper tangent arc (probably often mistaken for part of a $22^{\circ}$ halo) and one $17^{\circ}$ solar halo.

\section{E. Blackwell.}

J. C. W. DE LA Bere.

I1 Victoria Road,

Farnborough, Hants.

${ }^{2}$ Nature, 154, 433 (1944).

"Pernter-Exner, "Meteorologische Optik".

\section{Prof. A. E. Conrady}

I AM indebted to Mr. Cyril Young, of Sir Howard Grubb, Parsons and Co., Ltd., for directing my attention to a mis-statement in my obituary notice of the late Prof. Conrady ${ }^{1}$. I had been informed from a source which $\mathrm{I}$ believed trustworthy that, prior to the War of 1914-18, the periscopes fitted to British submarines had been obtained from foreign sources. Mr. Young, supported by other correspondents, assures me that almost all the periscopes of this period were made by the firm of Sir Howard Grubb and Sons, Ltd., in Dublin ; and this firm produced the majority of the periscopes used during the War. Even before 1914, periscopes were the main product of the firm, though it was probably better known in scientific circles for its astronomical telescopes. Sir Howard Grubb took out a number of patents in connexion with submarine periscopes from the year 1901 onwards. The firm's workshops were removed from Dublin to St. Albans when the enemy submarine menace became acute.

This does not, of course, detract from the merit of Prof. Conrady's original work in the design of such complicated systems (his designs were not of the 'Grubb' type) and his efforts, together with those of the optical staff of the National Physical Laboratory, Messrs. W. Watson and Sons, Ltd., and Messrs. Kelvin, Bottomley and Baird, Ltd., must have contributed very largely to the adequate supply of these essential parts of submarine equipment. Their manufacture was later taken up by Messrs. Barr and Stroud, Ltd.

It is clear that Great Britain owes a great debt to the late Sir Howard Grubb in this connexion. L. C. Martin.

Imperial College of Science and Technology, London, S.W.7.

${ }^{1}$ Nature, 154, 173 (1944). 